\title{
Juventudes e participação social: processos de socialização na contemporaneidade
}

\author{
Youths and social participation: contemporary socialization processes \\ Juventud y participación social: procesos de socialización contemporáneos
}

Maurício Perondi*

\section{Resumo}

O presente artigo trata da socialização de jovens a partir da sua participação em quatro coletivos: Instituto Gaúcho de Estudos Ambientais (Ingá), Cursinho Pré-Vestibular Zumbi dos Palmares, Instituto Cultural Afro Sul/Odomodê e Campanha Nacional Contra a Violência e o Extermínio de Jovens, das Pastorais da Juventude do Brasil. Busca compreender os sentidos que a participação nesses grupos tem para a vida dos jovens envolvidos. Seus referenciais são autores que discutem a socialização das juventudes contemporâneas, a partir dos conceitos de participação social e de culturas juvenis, tais como Carles Feixa, José Machado Pais, Alberto Melucci, Regina Novaes e Luis A. Groppo. A metodologia empreendida na investigação teve cunho qualitativo a partir das narrativas juvenis. Os resultados evidenciaram que os grupos contribuem significativamente para a socialização dos jovens, a partir das relações que estabelecem com outros sujeitos de mesma idade. A principal categoria produzida a partir dos dados analisados foi chamada de sociabilidade e tratou dos temas da coletividade, da convivência, da amizade e dos grupos como uma "segunda família".

Palavras-chave: juventudes; socialização; narrativas juvenis; participação social; culturas juvenis.

\section{Abstract}

This article deals with the socialization of young people based on their participation in four collectives: Gaucho Institute of Environmental Studies - Inga, Zumbi dos Palmares Preparatory Couse, Afro Sul/Idomode Cultural Institute, and National Campaign against Youth Violence and Extermination, of Youth Pastoral of Brazil. It aims to understand the meanings the participation in these groups has in the young people's lives involved. Its references are authors who discuss the socialization of contemporary youth from the concepts of social participation and youth cultures, such as Carles Feixa, Jose Machado Pais, Alberto Melucci, Regina Novaes, and Luis A. Groppo. The methodology used in the investigation was qualitative, based on youth narratives. The results showed that the groups contribute significantly to the socialization of young people, based on the relationships they establish with other subjects who are the same age. The main category produced from the analyzed data was called sociability and considered the themes of collectivity, coexistence, friendship, and groups as a "second family".

Keywords: youths; socialization; youth narratives; social participation; youth cultures.

Recebido em: 30/07/2020 - Aprovado em: 21/05/2021

http://dx.doi.org/10.5335/rep.v28i1.11500

Doutor em Educação. Professor na Faculdade de Educação da UFRGS, Porto Alegre. Orcid: http://orcid.org/0000-00020551-468X. E-mail: mauricioperondirs@gmail.com 


\section{Resumen}

Este artículo aborda la socialización de los jóvenes en función de su participación en cuatro grupos: Instituto Gaúcho de Estudios Ambientales - Ingá, Curso Pré-Vestibular Zumbi dos Palmares, Instituto Cultural Afro Sul/ Odomodê y Campaña Nacional contra la Violencia y lo Exterminio de Jóvenes, de las Pastorales de Juventud de Brasil. El objetivo de la investigación fue comprender cuáles son los significados que la participación en estos grupos representa para la vida de los jóvenes involucrados. Toma como referencia a autores que discuten la socialización de la juventud contemporánea, a partir de los conceptos de participación social y culturas juveniles, como Carles Feixa, José Machado País, Alberto Melucci, Regina Novaes, Luis A. Groppo, entre otros. La metodología utilizada en la investigación tuvo una naturaleza cualitativa, basada en narrativas juveniles. Los resultados mostraron que los grupos contribuyen significativamente a la socialización de los jóvenes, en función de las relaciones que establecen con otros sujetos de la misma edad. La categoría principal producida a partir de los datos analizados se denominó sociabilidad y trató los temas de colectividad, convivencia, amistad y grupos como una "segunda familia".

Palabras clave: jóvenes; socialización; narrativas juveniles; participación social; culturas juveniles.

\section{Introdução}

No limiar do século XXI, há um permanente questionamento acerca dos novos processos socializadores diante de um mundo globalizado, com diferentes configurações relacionais, impactos do mundo tecnológico e constantes mudanças sociais, que parecem se tornar cada vez mais velozes. Neste cenário, as instâncias tradicionais de socialização, como a família, a escola, o mundo do trabalho, passam a se questionar e a serem questionadas sobre o seu papel na formação das novas gerações, sobretudo das juventudes.

Para Groppo (2017), aconteceu um processo histórico de modificação nas percepções sobre as questões geracionais voltadas aos jovens. Na primeira parte do século XX, predominaram as teorias da sociologia estrutural-funcionalista da juventude, em que os grupos juvenis teriam uma função de socialização secundária, posterior à família e à escola. De acordo com o autor, na segunda metade do século XX, a ênfase voltou-se para as teorias críticas que desenvolveram, a partir de Foracchi (1972) e Mannheim (1982), a ideia de que "a juventude tem uma relação experimental com os valores e a realidade social. Deste modo, busca-se explicar os movimentos radicais e contraculturais dos anos 1960" (GROPPO, 2017, p. 17). Já no final do século XX e início do século XXI, surgem as chamadas teorias pós-críticas, caracterizadas por duas situações: a) "o reconhecimento do papel mais ativo dos sujeitos e grupos na constituição das juventudes” (GROPPO, 2017, p. 17); b) "processos de flexibilização e desinstitucionalização da vida social como a privatização e a descronologização do curso da vida, de modo que relativizam e até negam o caráter transitório da condição juvenil" (GROPPO, 2017, p. 18). 
A partir das mudanças de concepções das configurações juvenis nos processos de socialização ao longo do tempo, neste artigo são adotados dois pressupostos: 0 primeiro trata da participação social dos jovens na atualidade, problematizando a importância que os coletivos juvenis representam para este segmento social; o segundo discorre sobre as culturas juvenis (FEIXA, 2006) como forma de romper com a perspectiva unidirecional geracional de socialização dos jovens. Posteriormente, são apresentados os delineamentos metodológicos e resultados de uma pesquisa com narrativas juvenis sobre participação social em quatro coletivos, relacionados a quatro áreas que, segundo Novaes e Vital (2005), representam grande interesse para as juventudes contemporâneas. Os resultados mostram a configuração da importância que os grupos têm para os jovens participantes, bem como para os processos de socialização que deles decorrem.

\section{Juventudes e participação social}

Problematizar a participação social da juventude implica pensar o futuro democrático das sociedades latino-americanas. De acordo com Novaes e Vital (2005), os jovens são herdeiros dos símbolos, valores e códigos de funcionamento que a sociedade produz. Em grande parte, eles é que definirão os padrões de reprodução ou de mudanças das sociedades e de suas instituições. Na visão das autoras, "compreender a juventude de hoje é compreender o mundo de hoje" (NOVAES; VITAL, 2005, p. 109). Tal ideia aponta para a relação histórico-cultural da juventude, ou seja, ela está intimamente ligada ao período histórico e ao contexto cultural em que está inserida.

Para Krauskopf (2005, p. 151), "a construção da juventude na América Latina e no Caribe ocorre em meio a transições históricas e políticas, a contextos de desigualdades econômicas e a um forte influxo da globalização". A partir dessa afirmação, é preciso considerar que as percepções sobre os jovens não podem ser homogêneas, o que implica analisar os fenômenos que marcam as identidades dos jovens a partir de suas diferentes desigualdades. A realidade das tecnologias digitais é outro fator que integra o panorama das mudanças culturais, acentuando diferenças e contribuindo para o surgimento de novos códigos, condições e experiências para os processos de construção identitária dos jovens.

Compreender o momento presente tornou-se uma tarefa complexa e exigente, também para entender as mudanças ocorridas nos processos de socialização. Fischer e Sposito (2001, p. 15), inspirados por Melucci, apontam que, "diante das 
dificuldades de compreensão dos fenômenos que caracterizam a sociedade atual, recorremos apenas a definições alusivas, designando-a como complexa, globalizada, planetária, pós-industrial, de modernidade lenta ou pós-moderna”. Destacam que este esforço em nomear o momento vivido busca perceber os processos de mutação social inconclusos, dos quais nos falta um distanciamento histórico que permita explicá-los em sua totalidade. Mesmo com esta dificuldade de definição, Melucci (apud FISCHER; SPOSITO, 2001, p. 15, grifo nosso) aponta para três traços básicos que caracterizam a sociedade contemporânea:

Diferenciação: traduzida pela multiplicação dos âmbitos da vida e forma de estruturas específicas para responder a tarefas que anteriormente eram desenvolvidas por estruturas mais simples e homogêneas; variabilidade: percebida pelo conjunto de alterações na dimensão temporal em função da intensidade e do ritmo contínuo da mudança; excedente cultural: que exprime o fato de que as possibilidades simbolicamente disponíveis à ação dos indivíduos são muito mais amplas do que sua própria capacidade de ação.

A diferenciação exprime a multiplicidade de âmbitos e instituições que permeiam a vida das pessoas atualmente. Percebe-se uma ampliação de estruturas e instituições, tais como novas associações, novos espaços de lazer, o surgimento de espaços públicos, a rua como área de encontro e criação e o crescimento de grupos informais. Anteriormente, a vida cotidiana era constituída por estruturas mais simples e homogêneas, tais como a família, a escola, a igreja, e o mundo do trabalho, que se destacavam como os principais, quando não os únicos, espaços responsáveis pela socialização dos jovens. Hodiernamente, essas mesmas instituições não se apresentam de forma homogênea, sendo que cada uma exprime novas configurações, formatos, valores e opções. Tais mudanças repercutem na vida dos sujeitos e nos modos como se situam diante delas.

A variabilidade compreende os modos como os processos temporais são vivenciados, principalmente em relação à intensidade e ao ritmo contínuo das mudanças. O tempo é vivenciado de uma maneira diferenciada, até então não experimentada, onde tudo é acelerado e volátil. Diz-se que em outros tempos a mudança de uma geração para outra acontecia a cada vinte anos, ao passo que, atualmente, diz-se que tal diferença diminuiu para aproximadamente seis anos.

O excedente cultural diz respeito às inúmeras possibilidades simbolicamente disponíveis a que os indivíduos não têm capacidade de absorção. Isto é, não é possível acompanhar e usufruir tudo o que é produzido, seja em termos cognitivos ou culturais, seja em termos materiais. 
Estes traços exercem grande influência sobre a vida dos jovens em suas relações cotidianas. Eles estabelecem novos parâmetros para pensar o conceito de juventude, visto que a diferenciação, a variabilidade e o excedente cultural têm reflexos distintos na vida de jovens que, embora tenham a mesma faixa etária, vivenciam realidades e situações distintas.

Almeida (2009, p. 121), inspirado em Melucci, destaca que:

Para melhor entender as tendências emergentes da cultura e da ação juvenil temos que considerá-las mediante a combinação de uma perspectiva macrossociológica entrelaçada às experiências individuais na vida diária, pois a juventude, em decorrência de suas condições culturais e biológicas, é o conjunto social mais diretamente exposto aos dilemas da construção histórica do tempo e da realidade social na contemporaneidade, o grupo que os torna visíveis para a sociedade como um todo.

Tal afirmação aponta para a necessária vinculação dos jovens com a sociedade em que estão inseridos. Por sua condição, eles tornam visíveis problemas e contradições que são produzidos no interior desta mesma sociedade. Por esse motivo, a juventude também é apontada como "espelho retrovisor da sociedade" (NOVAES; VITAL, 2005). Ou seja, ela vive e expressa aquilo que lhe cerca no seu cotidiano.

Esta sociedade, que está refletida na expressão dos jovens, é chamada de sociedade complexa (MELUCCI, 2001). Sua perspectiva é a de que, principalmente a partir dos anos 1980, a sociedade passa por uma profunda transformação em seus diversos aspectos, inclusive nas formas de participação dos movimentos sociais e na atuação dos indivíduos que buscam mudanças. Para Melucci (2001, p. 10-11):

Não nos encontramos diante da dissolução dos atores coletivos ou do desaparecimento dos conflitos, mas de uma mudança profunda de sua forma. [...]. Estamos, certamente, diante do desaparecimento da ação e dos sujeitos que coincidem com a nossa ideia tradicional de movimento. [...]. A ideia de que só a mudança das estruturas pode produzir transformações, sem envolver os nossos modos de construir, individual e coletivamente, a mesma experiência humana, pertence às ilusões do passado.

A reflexão denota que os conflitos sociais e as atuações, tanto individuais como coletivas, continuam presentes na sociedade contemporânea, mas a sua forma se alterou consideravelmente. É preciso superar a ideia tradicional que se tem de participação. Se, historicamente, a concepção dominante era de que as transformações sociais passam pela necessária mudança das estruturas, nas sociedades complexas tal concepção é abandonada. Não há uma dissolução ou uma ausência de conflitos sociais, dada a sua escassa visibilidade. Outrossim, o que há é um esgotamento das modalidades de lutas e atores envolvidos.

Ainda segundo Melucci (2001, p. 95): 
Os movimentos juvenis, feministas, ecológicos, étnico-nacionais, pacifistas não têm somente colocado em cena atores conflituais, formas de ação e problemas estranhos à tradição de lutas do capitalismo industrial; eles têm colocado também, no primeiro plano, a inadequação das formas tradicionais de representação política para acolher de maneira eficaz as questões emergentes.

O apontamento do autor destaca que os novos movimentos da sociedade contemporânea deixam para trás as formas tradicionais de representação política e de atuação diante das demandas de ação coletiva. Isso se deve também ao fato de que os movimentos não são unidades coletivas homogêneas, mas são compostos por unidades diversificadas e autônomas, que dedicam à sua solidariedade interna uma parte importante dos seus recursos.

Com a ampliação das possibilidades para a socialização das novas gerações, sobretudo através do advento da internet, do crescente crescimento de uso das redes sociais e de outras possibilidades socializadoras, tornou-se comum o questionamento cético sobre o interesse dos jovens em participarem de coletivos e processos grupais. Contudo, de acordo com pesquisa realizada pela Secretaria Nacional de Juventude (2013), os jovens continuam muito interessados em participar de coletivos organizados, como é possível perceber no Gráfico 1.

Gráfico 1 - Histórico e desejo de participação em associações, entidades e grupos

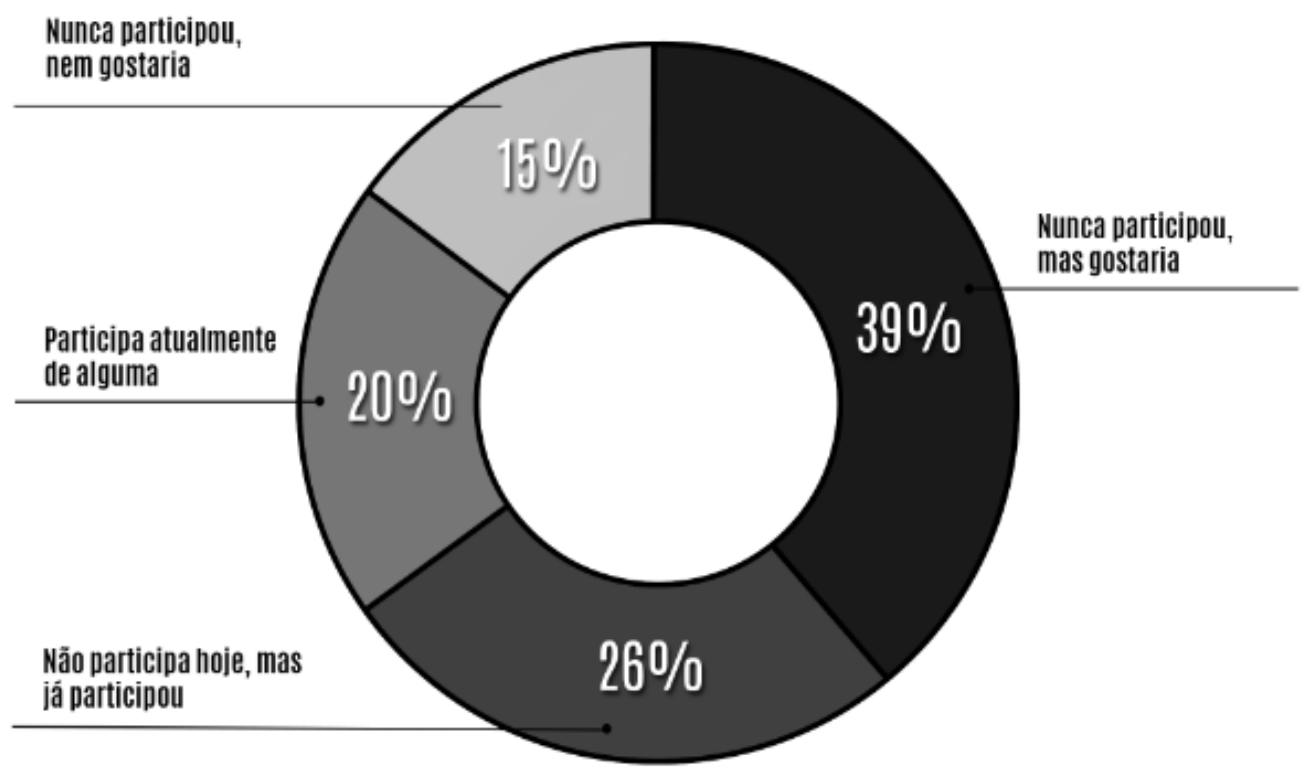

Fonte: adaptado por Adriene Maciel Cabral, a partir de Secretaria Nacional de Juventude (2013). 
De acordo com a pesquisa, se somados os jovens que participam de alguma organização (20\%), com os que já participaram (26\%) junto dos que nunca participaram, mas gostariam (39\%), resulta um total de $85 \%$ de jovens envolvidos. É possível perceber ainda que apenas $15 \%$ dos jovens entrevistados afirmaram que nunca participaram nem têm interesse em participar. Esses dados demonstram a importância que os grupos, coletivos, entidades, associações, etc., têm para as juventudes.

Nos resultados da pesquisa doutoral apresentados neste artigo (PERONDI, 2013), pode-se ver como a participação juvenil em coletivos sociais estabelece sentidos para a sua socialização, para a construção de sua identidade e para a organização de seus projetos de vida. Na sequência, discute-se como os jovens, por meio da convivência com outros sujeitos da sua idade, produzem processos próprios, que se diferenciam dos processos dos adultos e que são as culturas juvenis.

\section{A importância das culturas juvenis nos processos de socialização}

Para Feixa (2006), existem duas formas principais de situar os jovens socialmente. A primeira corresponde a uma construção sociocultural do que é o juvenil a partir das instituições hegemônicas (família, escola, trabalho, instituições religiosas, partidos políticos, associações intermediárias, exército, indústria cultural, meios de comunicação de massa, órgãos de vigilância e controle social). De modo geral, estas instituições têm definido os jovens como sujeitos passivos, que devem preparar-se e qualificar-se para acessar, no futuro, a esfera adulta. Esta projeção de lugar no futuro invisibiliza os jovens no presente (FEIXA, 2006). As instituições seriam as principais senão as únicas - responsáveis pela socialização das novas gerações. A segunda forma de situar os jovens é a da construção juvenil da cultura, que corresponde aos territórios de sociabilidade juvenil, criados pelos próprios jovens nos interstícios dos espaços institucionais, como a escola, a indústria do entretenimento, o bairro e, sobretudo, em seus tempos livres (rua, cinema, música, festas, internet, lugares de diversão, etc.). O diferencial desta segunda maneira é que os jovens, via interação com seus pares, participam dos processos de criação e de circulação cultural e social como agentes ativos.

De acordo com Urteaga (2011), essa segunda maneira de compreender os jovens corresponde à noção das culturas juvenis, que teve grande impulso com os estudos do antropólogo catalão Carles Feixa, convertendo-se numa importante chave interpretativa da heterogeneidade cultural dos jovens e de sua participação na construção de novos espaços sociais que interagem com as culturas hegemônicas 
e com as próprias culturas geracionais. Segundo Urteaga (2011, p. 19, grifo da autora, tradução nossa):

Culturas juvenis foi uma noção vital para reintroduzir o sujeito jovem como ator e poder fazer ouvir as vozes dos segmentos juvenis marginalizados da investigação social. Feixa, Reguillo, Pere Islas, Valenzuela, Marcial, Urteaga (quem lhes escreve) e muitos outros investigadores enfatizamos a importância de ler as representações e práticas juvenis como metáforas da mudança social, rompendo com as interpretações lineares e "fazendo falar" o conjunto de elementos com os quais os jovens interagem - desde diferentes âmbitos e localizando-se em múltiplas dimensões como classe, gênero, geração, etnia, território, espaço urbano-rural - e com os quais constroem novas formas e concepções de política, de relações sociais e afetivas, de cultura, etc.

Tal apontamento enfatiza o uso de noção das culturas juvenis na compreensão das abordagens recentes sobre os jovens, em que são situados de uma maneira diferenciada, com maior visibilidade e a partir do pressuposto de que produzem uma cultura diferente de outras (hegemônica e parental).

Ao conceber os jovens como produtores de uma cultura própria, considera-se que são sujeitos ativos, dotados de capacidade de ação. Suas ações podem ganhar espaço nos mais diversos âmbitos, inclusive em coletivos de atuação social, como é o caso dos grupos abordados neste estudo (PERONDI, 2013). Para o aprofundamento temático das culturas juvenis, têm-se como referência as formulações de Feixa (2006), autor com reconhecida produção na área.

A maneira plural como os jovens vivem suas vidas depende de diversos fatores, como as condições sociais, as relações que estabelecem e as oportunidades que lhes são oferecidas. Por mais que existam diferentes juventudes, os jovens não vivem este momento de forma isolada, mas através de aproximações com seus coetâneos, que buscam respostas semelhantes às suas, ocasionando o surgimento das culturas juvenis. Para Feixa (2006, p. 105, tradução nossa), estas culturas podem ser compreendidas em sentido amplo e em sentido restrito:

Em um sentido amplo, as culturas juvenis referem-se à forma como as experiências sociais dos jovens se expressam coletivamente por meio da construção de estilos de vida distintos, localizados principalmente no tempo livre, ou em espaços intersticiais da vida institucional. Num sentido mais restrito, definem o surgimento de "micro-sociedades juvenis", com expressivos graus de autonomia em relação às "instituições adultas", dotadas de espaços e tempos específicos, e que se configuram historicamente nos países ocidentais a partir da Segunda Guerra Mundial, coincidindo com grandes processos de mudança social nos campos econômico, educacional, trabalhista e ideológico.

O sentido amplo, apontado pelo autor, remete às experiências sociais que os jovens expressam coletivamente a partir da construção de estilos de vida e ma- 
neiras de conviver, que acontecem especialmente no tempo livre e nos espaços intersticiais das instituições em que participam. $\mathrm{O}$ estrito refere-se ao surgimento de microssociedades juvenis, que se caracterizam por certo grau de autonomia em relação às instituições adultas. Essas microssociedades se expressam através de diferentes agrupamentos juvenis com seus processos de identização, singularização e relações entre seus membros. Apesar de serem constituídas por participantes com diferentes experiências, apresentam elementos afins, que são capazes de mobilizar a participação dos jovens em uma determinada microssociedade.

Segundo Feixa (2006), a noção de culturas juvenis remete ao conceito de culturas subalternas, o que, na tradição gramsciana da antropologia italiana, corresponde aos setores dominados, que se caracterizam por sua precária integração com a cultura hegemônica. A falta de integração ou integração parcial nas estruturas produtivas e reprodutivas é uma das características essenciais das juventudes. Geralmente, os jovens, inclusive os que provêm das classes dominantes, têm pouco controle sobre a maior parte dos principais aspectos de sua vida e estão submetidos à tutela de instituições adultas. Ainda, conforme o autor, o que diferencia a condição juvenil de outras condições sociais subalternas, como dos camponeses, das mulheres e das minorias étnicas, é que se trata de uma condição transitória, visto que, posteriormente, os jovens passam a ser adultos. Esse caráter transitório tem sido utilizado em muitas ocasiões para menosprezar ou desqualificar os discursos culturais dos jovens. Apesar disso, e com condições desiguais de poder e recursos, determinados grupos juvenis têm sido capazes de manter níveis de autoafirmação consideráveis (LUTTE, 1984; JULIANO, 1985 apud FEIXA, 2006).

Na perspectiva proposta por Feixa (2006, p. 106 et seq.), a articulação social das culturas juvenis pode ser abordada a partir de três cenários:

a) Culturas hegemônicas: representam a distribuição do poder cultural no âmbito da sociedade mais ampla. A relação dos jovens com a cultura dominante é mediada por diversas instâncias nas quais este poder se transmite e negocia, tais como a escola, o mundo do trabalho, o exército e os meios de comunicação. Constituem-se como as principais instâncias responsáveis pela socialização e educação das novas gerações. Diante dessas culturas, os jovens estabelecem relações contraditórias de integração e conflito, que se modificam com o passar do tempo.

b) Culturas parentais: podem ser consideradas como as grandes redes culturais, definidas fundamentalmente por identidades étnicas e de classe, a partir das quais se desenvolvem as culturas juvenis, constituindo subconjuntos. Re- 
ferem-se às normas de conduta e aos valores vigentes no meio social de origem dos jovens. Não se limitam a uma relação direta entre pais e filhos, mas a um conjunto mais amplo de interações cotidianas entre membros de gerações diferentes, dentro da própria família, dos vizinhos, da escola local, das redes de amizade, das associações, etc. Diante desta socialização primária, os jovens interiorizam elementos culturais básicos (uso da língua, papéis sexuais, formas de sociabilidade, comportamento não verbal, critérios estéticos, etc.) que, posteriormente, utilizam na elaboração de estilos de vida próprios.

c) Culturas geracionais: referem-se à experiência específica que os jovens adquirem nos interstícios dos espaços institucionais (amigos da escola, da igreja, do trabalho), dos espaços parentais (relações familiares ampliadas, vizinhança) e, sobretudo, dos espaços de ócio (a rua, as festas, as redes sociais, os locais de diversão). Nesses espaços, eles se encontram com outros jovens e começam a se identificar com determinados comportamentos e valores, diferentes daqueles vigentes no mundo adulto. De modo especial, nessas culturas os processos de socialização se ampliam, pois as relações são estabelecidas prioritariamente com outros jovens que têm a mesma idade e não com os adultos que estão nestes espaços.

Além dos três cenários descritos, o autor destaca outros fatores na estruturação das culturas juvenis, tais como a geração, o gênero, a classe, a etnicidade, o território e o estilo (bricolagem, homologia, linguagem, música, estética, produções culturais, atividades focais). Feixa (2006) traduz a sua perspectiva conceitual a partir de uma imagem gráfica que utiliza como uma metáfora, em que as culturas juvenis podem ser representadas. Trata-se do relógio de areia (ampulheta) que mede o tempo (Figura 1). 
Figura 1 - Metáfora do Relógio de Areia

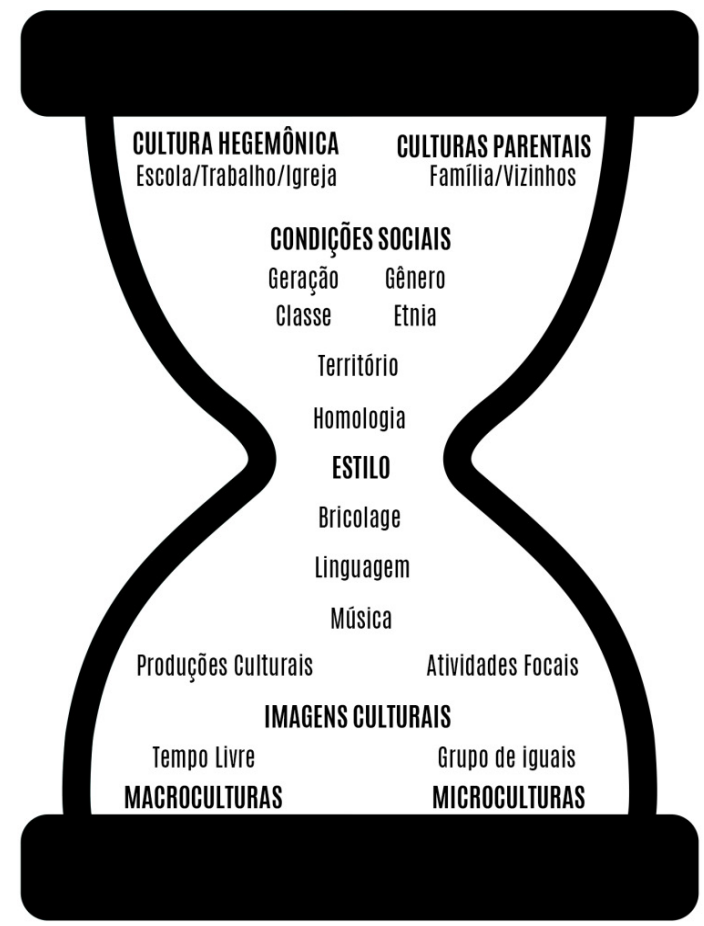

Fonte: adaptado por Adriene Maciel Cabral, a partir de Feixa (2006, p. 126).

Segundo o autor, no plano superior estão situadas as culturas hegemônicas e as culturas parentais, com seus respectivos espaços de expressão (escola, trabalho, meios de comunicação, família, vizinhança). No plano inferior, encontram-se as culturas e microculturas juvenis, com seus espaços próprios (tempo livre, grupos de amigos). Os materiais da base (a areia inicial) constituem as condições sociais de geração, gênero, classe, etnia e território. Na parte central, o estilo filtra estes materiais mediante técnicas de homologia e bricolagem. As imagens culturais resultantes (a areia filtrada) se traduzem em linguagem, estética, música, produções culturais e atividades focais. Essa metáfora ilustra tanto o caráter histórico das culturas juvenis como a sua dimensão biográfica. Por outro lado, também evidencia que as relações não são unidirecionais, pois, quando a areia acaba de descer, pode-se virar a ampulheta, de modo que as culturas e microculturas juvenis mostram também sua influência na cultura hegemônica e nas culturas parentais.

A influência das culturas juvenis nos contextos das culturas hegemônicas e parentais pode ser percebida claramente nos coletivos examinados neste artigo. Mesmo 
que sejam grupos não exclusivamente juvenis, os sujeitos jovens participantes da pesquisa manifestam que, há nesses coletivos, espaços de autoria e de desenvolvimento de liderança, pois chegam a ocupar determinadas posições de direção. Ao mesmo tempo que enfatizam uma diferenciação diante de participantes de outras gerações ou mesmo diante da própria instituição, também destacam um profundo sentido de pertencimento e identificação com o grupo e com suas causas, enfatizando a importância das relações intergeracionais estabelecidas em seu âmbito.

Pensando nos processos de socialização, pode-se conceber que os jovens, através das culturas juvenis, contribuem uns com os outros em suas dinâmicas pessoais de crescimento e de constituição de si. Tal fenômeno amplia a visão clássica de que a socialização só acontece mediante a ação das instituições ou das gerações adultas, visto que, nesse caso, os próprios jovens são sujeitos desse processo. Isso não significa que as instituições e o mundo adulto não têm mais um papel importante, mas que suas constituições foram reconfiguradas e, em muitos casos, não detêm mais a hegemonia socializadora.

\section{Metodologia da pesquisa}

A pesquisa que originou este trabalho é oriunda de um curso de Doutorado em Educação (PERONDI, 2013) e contou com a participação de jovens integrantes de coletivos sociais, da região metropolitana de Porto Alegre. Trata-se de um estudo qualitativo, que desenvolveu análise compreensiva na busca da percepção sobre o que os jovens narram a partir de suas experiências de participação social.

Para o desenvolvimento da investigação, tomou-se como referência a afirmação de Novaes e Vital (2005), de que, neste início de século XXI, existem quatro áreas - chamadas pelas autoras de consignas - que motivam expressivamente a participação de jovens: a ecológica, a educacional, a dos grupos com vulnerabilidades específicas e a da paz e direitos humanos. Para cada uma das áreas, escolheu-se um coletivo que contasse com a participação de jovens em sua organicidade.

Os quatro coletivos escolhidos foram:

a) Instituto Gaúcho de Estudos Ambientais (Ingá). Organização não governamental começada em 1999 por iniciativa de um grupo de pesquisadores e ambientalistas, em sua maioria biólogos. Desenvolve atividades de formação ambiental, participa de conselhos representativos das questões ambientais, participa de feiras ecológicas e de atividades de biodiversidade. Os jovens participantes são estudantes, filhos de agricultores do interior do estado, militantes da causa ecológica, entre outros. 
b) Cursinho Pré-Vestibular Zumbi dos Palmares. Teve início em 1995 junto a uma associação comunitária da Vila Cruzeiro, de Porto Alegre. Inspirou-se na iniciativa do frei David Raimundo dos Santos, que criou cursinhos pré-vestibulares com perspectiva pedagógico-popular, no início da década de 1990, na Baixada Fluminense, Rio de Janeiro. Seu objetivo é de preparar jovens das classes populares para ingressar no ensino superior.

c) Instituto Cultural Afro Sul/Odomodê. Foi criado em 1999 partir da proposição de um trabalho social que valorizasse a cultura negra, procurando superar a vinculação estritamente ao carnaval. O nome foi escolhido pelo seu significado na língua yorubá: Odomode = jovem, novo, garoto. Entre as atividades realizadas, destacam-se a dança, a música, a moda e a gastronomia, todas elas retratando a cultura afro-gaúcha. Os participantes são adolescentes, jovens de rua e jovens de comunidades carentes que têm a oportunidade de aprender e de praticar a cultura afro-brasileira com o trabalho social desenvolvido pelo grupo.

\section{d) Campanha Nacional Contra a Violência e o Extermínio de Jovens.} Campanha das Pastorais da Juventude do Brasil, vinculadas à Igreja Católica, é uma ação coordenada principalmente por jovens, articulada com diversas organizações, para levar a toda sociedade o debate sobre as diversas formas de violência contra a juventude, especialmente o extermínio de milhares de jovens em curso no Brasil.

Adotou-se a metodologia das narrativas juvenis como proposta principal de investigação através da qual foram produzidos relatos de jovens dos quatro coletivos acerca dos sentidos de sua participação e como eles repercutem em suas vidas. O objetivo central da investigação foi compreender, a partir dos próprios jovens, como eles significam suas participações nestes espaços e como repercutem em suas vidas. As perguntas que permearam o estudo foram: Que sentidos os jovens narram a partir das diferentes experiências de participação social? O que pensam que mudou em suas vidas ao participarem desses grupos? Suas vidas seriam diferentes se não participassem destes coletivos?

De acordo com Melucci (2005, p. 29):

Na vida cotidiana, os indivíduos constroem ativamente o sentido da própria ação, que não é mais somente indicado pelas estruturas sociais e submetido aos vínculos da ordem constituída. O sentido é sempre mais produzido através de relações e esta dimensão construtiva e relacional acresce na ação o componente de significado na pesquisa. 
O autor aponta que no mundo contemporâneo os indivíduos constroem ativamente os sentidos de suas ações a partir dos diversos âmbitos da vida cotidiana, não se limitando aos indicativos das estruturas sociais e da ordem estabelecida. Cabe, portanto, às pesquisas de cunho qualitativo investigar os sentidos que os sujeitos constroem a partir das relações que estabelecem nos espaços que ocupam. Essa foi a perspectiva adotada neste estudo, em que se buscou compreender, a partir das próprias narrativas dos jovens, os sentidos que eles atribuem à sua participação nos grupos, independentemente dos objetivos e características particulares.

Na sequência, são apresentados alguns dos principais dados resultantes da investigação realizada com 20 jovens dos coletivos sociais, destacando-se os aspectos que contribuem para pensar no processo de socialização dos jovens contemporâneos. Os dados foram produzidos através da execução de cinco fases: a) definição de quatro coletivos participantes; b) formação de uma equipe de jovens que contribuíram para a pesquisa; c) realização de um curso com os jovens participantes, intitulado "Juventude, participação social e narrativas juvenis"; d) coleta das narrativas dos jovens sobre suas experiências de participação; e) discussão dos resultados da pesquisa.

Dada a limitação espacial, neste artigo não é possível apresentar toda a amplitude dos resultados alcançados. Em vista disso, optou-se por destacar os principais aspectos relacionados aos processos de socialização dos jovens a partir dos grupos em que eles participavam.

\section{Participação coletiva e a contribuição nos processos de socialização juvenil}

De acordo com a realização da análise dos dados, uma das categorias construídas e selecionadas foi a da sociabilidade. Por meio dela, os participantes expressaram situações e significados das relações que estabelecem nos grupos. A partir da definição dessa categoria, foram desenvolvidos os seguintes temas: a coletividade, a convivência, a amizade e a segunda família, os quais são aprofundados na sequência. Segundo Urteaga (2011, p. 38, grifo da autora), a "sociabilidade funciona como uma argamassa afetiva dos grupos, dos movimentos, dos coletivos, das identidades e das culturas juvenis". Esta argamassa possibilita a coesão do grupo e a sua possibilidade de união em torno dos objetivos buscados pelo coletivo.

O primeiro tema analisado foi a coletividade. A partir dele, uma das jovens participantes da pesquisa afirma: 
O sentido de estar aqui é justamente isso, é tu estar com pessoas que tu sabe que tem os ideais semelhantes. Por exemplo, em algumas empresas que eu já trabalhei eu não encontro isso. Eu não quero comparar o InGá com uma empresa, mas sim com os grupos em que a gente participa. Mesmo no dia a dia, com os teus vizinhos ou com alguns amigos que tu acaba fazendo, mesmo eles, às vezes não tem os mesmos objetivos que tu tem na vida, de construir uma sociedade mais justa, com respeito ao meio ambiente e tudo isso... A gente não encontra esses objetivos em qualquer pessoa por aí. Então essa que é a moral de eu estar aqui também né, por saber que eu posso contar com estas pessoas pra, sei lá, viabilizar este mundo melhor que a gente gostaria que existisse. (Paloma, InGá).

A sua narrativa constitui um exemplo emblemático para compreender a dimensão da coletividade para os jovens. A jovem destaca que teve contato com vários grupos, mas em nenhum deles conseguiu encontrar ideais semelhantes e um espírito coletivo como no InGá. Outra expressão marcante em seu relato é a contar com pessoas com as quais pode viabilizar um mundo melhor que gostaria que existisse. Esta situação de compartilhar objetivos comuns vem ao encontro do que Pais (2003, p. 119) afirma: "A coesão interna dos grupos estabiliza-se a partir de traços de identificação conjuntamente compartilhados; no entanto, esses traços funcionam também como suporte de formação e reconhecimento de identidades grupais entre si diferenciadas".

$\mathrm{O}$ apontamento do autor sugere que, a partir de objetivos conjuntamente compartilhados, os grupos tendem a estabelecer uma coesão interna, que funciona como suporte aos sujeitos e aos próprios coletivos. Esta perspectiva parece ser a que a jovem Paloma encontrou no InGá e não em outros espaços onde atuou ou que conheceu, ao afirmar que não se encontra isso em qualquer grupo.

Ao falar do tema, outro jovem assim se expressou:

É muito importante o trabalho do grupo, sabe. Eu vejo que dá sentido para a minha ação. Meu trabalho é um trabalho coletivo, ou seja, não é o meu trabalho, é o trabalho do grupo. E o jeito que a gente tem trabalhado é cada um dar um pouquinho; então a ideia é fortalecer, vamos somar, vamos multiplicar. (Vinícius, InGá).

Segundo Vinícius, o trabalho do grupo é de grande valia. Ele enfatiza que o seu trabalho não é individual, mas coletivo e que, no grupo, cada um procura contribuir com sua parte para fortalecer o conjunto. Esta é a dimensão destacada por Pais (2003, p. 121, grifo do autor) ao escrever que:

A individualidade de cada um dos elementos é assegurada: no entanto, a participação no grupo envolve uma negociação e aceitação tácita relativamente aos hábitos do grupo, pressuposto necessário à manutenção da coesão do grupo: as relações de compromisso com o grupo tendem a subsumir divergências individuais. 
Assim, na relação grupal a identidade é preservada. Contudo, pode ocorrer uma negociação em que o sujeito aceita as regras do grupo, tendendo a eliminar as divergências pessoais e fortalecendo a coesão grupal. Tal dinâmica pode ilustrar o relato do jovem Vinícius, quando afirma que "cada um dá um pouquinho", visando fortalecer o grupo.

O segundo tema de análise chamou-se "convivência". Ao falar dele, um dos jovens apontou:

Ela [Equipe de Coordenação da Campanha] é uma equipe de muito trabalho, que exige uma dedicação semanal, não diária, mas de dedicação pra estar dando conta de e-mails, dando conta de atualizações, estar ligando, estar conversando. Então a Equipe da Campanha pra mim se torna pelo contato que eu tenho com algumas pessoas, ela se torna primeiro um espaço de trabalho, mas como nós somos jovens, além de trabalhar nós também temos que conviver e a equipe acaba se tornando um espaço de convivência. A equipe em si é uma equipe de muito trabalho, é uma equipe que trabalha muito, que encaminha muita coisa, que me faz trabalhar e me coloca pra trabalhar em conjunto também, aí a gente vai se encontrando, vai fazendo a vida, não só de trabalho. (Roger, Campanha contra a Violência e o Extermínio de Jovens).

O relato pormenorizado de Roger ressalta que, além do intenso trabalho desenvolvido na coordenação da citada campanha no Rio Grande do Sul, da qual ele é integrante, que os membros da equipe são jovens e necessitam de espaço de convivência. Estes momentos se tornam imprescindíveis para eles, pois uma das características das culturas juvenis é que estas "se expressam coletivamente mediante a construção de estilos de vida distintos, localizados fundamentalmente no tempo livre e nos espaços intersticiais da vida institucional" (FEIXA, 2006, p. 105, tradução nossa). Deste modo, o jovem destaca que os momentos de convívio foram demarcadores na sua experiência de participação na equipe da campanha.

Outro jovem descreve, nos seguintes termos, a sua experiência:

A partir do momento que a gente levou o InGá para dentro do Casarão do Arvoredo, para aquela comunidade ali, isso trouxe outra identidade para o InGá, criou outros vínculos, outras relações. O InGá passou a ter mais coerência no seu trabalho; é a leitura que eu faço, é como eu enxergo a coisa; a gente conseguiu buscar junto mais coerência no trabalho, ou seja, algumas pessoas do InGá, é claro que não são todas que tem um convívio direto ali com a comunidade. Algumas pessoas do InGá passaram a ter toda uma outra descoberta assim da alimentação diretamente relacionada à agroecologia. Tudo isso vai transformando a pessoa, vai transformando o discurso da pessoa, formando a prática da pessoa. Então isso aí tudo tem a ver com o meu papel dentro do InGá; o meu papel é trazer esta visão mais cotidiana, da prática do dia-a-dia, da coerência daquilo que a gente fala com aquilo que a gente faz. Esse aí é o desafio pra mim. (Miguel, InGá). 
Em seu relato, o jovem Miguel destaca a importância da mudança do InGá para o Casarão do Arvoredo, sede do grupo e vários jovens também residem. Ele acrescenta que a convivência e as práticas geradas naquele espaço constituíram uma nova forma de relação entre os membros e para as posturas individuais dos sujeitos, numa dialética constante entre discurso e prática. Sua narrativa pode ser relacionada com o que Ricoeur (2007, p. 58) escreve:

Assim, as "coisas" lembradas são intrinsecamente associadas a lugares. E não é por acaso que dizemos, sobre uma coisa que aconteceu, que ela teve lugar. É de fato nesse nível primordial que se constitui o fenômeno dos "lugares de memória", antes que eles se tornem uma referência para o conhecimento histórico.

O pensador francês examina os lugares de memória, pois as experiências recordadas sempre são associadas a determinados lugares. Neste contexto, Miguel lembra das situações e dos momentos de convivência no Casarão do Arvoredo como um aspecto marcante na sua trajetória e de outros membros do seu grupo.

O terceiro tema analisado é a amizade, a qual é referida pela maioria dos participantes da pesquisa, evidenciando a sua centralidade nas experiências grupais juvenis. Ao falar do tema, uma das jovens afirma:

Uma experiência marcante na parte pessoal são as amizades, porque não tem o que pague, não tem coisa melhor, tu poder confiar em alguém e ter confiança recíproca. Também tem a parte de estar sempre recebendo informações de alguma maneira, acho que é isso que contribui no meu cotidiano, a minha aprendizagem e a amizade: aprendizade [risos]. (Érica, InGá).

Ao criar o neologismo "aprendizade", Érica aponta para a dimensão fundamental que a amizade representa na relação entre os jovens. De acordo com Ortega (2002), a amizade não significa apenas igualdade e concordância de ideias e gostos, mas que ela representa um exercício do político por meio do qual os jovens experimentam maneiras de sociabilidade e comunidade, ampliando as formas tradicionais de relacionamento. No caso do coletivo Ingá, um indicativo é de que as relações de amizade construídas em seu interior possibilitam o crescimento pessoal dos seus membros através dos aprendizados desenvolvidos entre eles.

Os dois relatos a seguir também focalizam a dimensão da amizade:

O que me motiva a permanecer no grupo é que, pra mim, dançar é como uma válvula de escape. É uma forma que eu tenho de me aliviar, aliviar minhas tensões, meu stress, de me relacionar com pessoas que eu gosto, de estar perto das minhas amigas, que são as meninas do grupo. (Letícia, Grupo Afro Sul/Odomodê)

O que me motiva a continuar é que aqui dentro tem muita parceria, muita amizade, então isso não me dá motivos pra sair do grupo. (Fabrício, InGá). 
Os jovens Letícia e Fabrício enfatizam a importância da amizade nas relações pessoais com o grupo. Destacam que este é um aspecto agregador em sua trajetória. A amizade é uma palavra que possui uma longa história no âmbito das relações humanas, tendo iniciado ainda com a philía dos filósofos gregos e atravessa toda a cultura ocidental posterior ${ }^{1}$. A amizade também pode ser associada às "necessidades afetivas, comunicativas e de solidariedade" (MELUCCI, 2001, p. 98) sentidas pelos sujeitos e que encontram correspondências nas relações que os jovens estabelecem com seus pares, como relatam os entrevistados.

O último tema componente da discussão sobre a sociabilidade foi designado como "segunda família". Nele, os jovens expressam uma forte relação com seus coletivos, chegando a chamá-los de uma nova ou segunda família. Os jovens assim se expressam a respeito do tema:

O Zumbi é como se fosse a minha segunda casa. Acho que eu não seria, talvez, essa pessoa que eu sou hoje, se eu não tivesse esse relacionamento com alguns, com o pessoal do Zumbi. É superimportante estar aqui. Embora eu não participe muito diretamente, me sinto vinculado, me sinto "da família". (Igor, Cursinho Pré-Vestibular Zumbi dos Palmares).

O amor no grupo isso é o mais significativo. Acho que justamente o que a gente tem buscado construir no InGá são relações humanas significativas. É mais importante que a gente esteja bem, unido e fortalecido, não só em termos de trabalho, mas também pessoalmente né. É uma grande família. Eu vejo assim, tranquilamente eu vejo assim. Eu quero que seja assim, mas às vezes, já foi dito que não seria interessante e tal, mas é o caminho que as coisas seguiram. Então eu me sinto acolhido, me sinto fortalecido, me sinto apoiado. É muito importante pra mim. (Vinícius, InGá).

Os depoimentos destacam os fortes laços estabelecidos pelos jovens no interior dos coletivos de que participam, chegando a considerá-los uma segunda casa ou uma grande família. Apontam o amor, a acolhida e a vinculação com os demais como um aspecto tão intenso que se assemelha às relações parentais. Tal proximidade sugere que suas trajetórias são fortemente afetadas pelas relações estabelecidas no grupo.

Ao abordar as relações juvenis em grupos com os quais desenvolveu investigações, Pais (2003, p. 39) afirma:

Para os jovens, as práticas de interação e de afetividade assumem um papel muito importante na construção de seus novos "modos de estar juntos", em suas formas de agregar-se ou organizar-se e na constituição de suas identidades individuais e coletivas.

De acordo com o autor, os jovens constroem novos modos de estar juntos a partir das interações e de afetividades que experimentam nos grupos. Essa ideia 
pode ser associada àquilo que os jovens da pesquisa referem como "segunda casa" ou "grande família", que se tornam elementos definidores das experiências juvenis nos respectivos coletivos.

\section{Considerações finais}

O presente artigo aborda as experiências de participação social de integrantes de quatro coletivos que contam com a participação de jovens. Entre outros elementos desenvolvidos, mostrou-se relevante o aspecto da sociabilidade entre os participantes dos grupos. Ficou evidente a importância que os coletivos continuam exercendo na constituição das identidades e nas relações que os jovens estabelecem nesses espaços.

Diante dos questionamentos presentes na sociedade contemporânea acerca dos desafios e das possibilidades de uma socialização não verticalizada, orientada para valores democráticos e para uma vida em comum, os jovens afirmam que a coletividade continua sendo fundamental para o seu desenvolvimento. Eles desejam e constroem relações em que as modificações acerca dos processos de socialização passam necessariamente por uma compreensão dos jovens como sujeitos sociais.

Por meio das culturas juvenis que produzem, os jovens contemporâneos se colocam como sujeitos ativos dos processos sociais, ou seja, além de serem influenciados pelas gerações hegemônicas e parentais, criam elementos culturais e identitários próprios. Essa construção passa sobretudo por dois aspectos fundamentais: o tempo livre e a relação com outros jovens de mesma faixa etária (FEIXA, 2006). Portanto, falas de adultos e posições institucionais de que os jovens "ficam muito tempo sem fazer nada" ou "perdem muito tempo navegando na internet" desconsideram que são nos espaços intersticiais de suas agendas extremamente cheias e organizadas que os jovens produzem suas próprias culturas e novas formas de socialização.

As instituições sociais não deixaram de ter um papel fundamental na socialização e na formação dos jovens. No entanto, os tempos e os modos sociais de fazê-lo se modificaram ou, em muitos casos, ainda precisarão se modificar. Talvez essa compreensão contribua para aprofundar outras formas de socialização e reduza conflitos intergeracionais que parecem impossíveis de serem transpostos. 
1 Para retratar as diferentes concepções de amizade, durante mais de vinte e quatro séculos, Francisco Ortega (2002) publicou Genealogia da amizade, último de uma série de três livros dedicados ao tema da amizade. Os demais títulos são: Amizade e estética da existência em Foucault (1999) e Para uma política da amizade: Arendt, Derrida e Foucault (2000).

\section{Referências}

ALMEIDA, Elmir. Os estudos sobre grupos juvenis: presenças e ausências. In: SPÓSITO, Marília Pontes (org.). O estado da arte sobre juventude na pós-graduação brasileira: educação, ciências sociais e serviço social (1999-2006). Belo Horizonte: Edvcere, 2009. v. 2. p. 121-173.

FEIXA, Carles. De jóvenes, bandas y tribus. 3. ed. Barcelona: Ariel, 2006.

FISCHER, Nilton Bueno; SPOSITO, Marília Pontes. Apresentação. In: MELUCCI, Alberto. A invenção do presente: movimentos sociais nas sociedades complexas. Trad. Maria do Carmo Alves do Bomfim. Petrópolis: Vozes, 2001. p. 13-20.

FORACCHI, Marialice M. A juventude na sociedade moderna. São Paulo: Pioneira; Edusp, 1972.

GROPPO, Luís A. Introdução à sociologia da juventude. Jundiaí: Paco Editorial, 2017.

JULIANO, Dolores. Uma subcultura negada: l'ambit domèstic. In: LLOPART, Prates y Prates (ed.). La cultura popular a debat. Barcelona: Alta Fulla, 1985. p. 39-48.

KRAUSKOPF, Dina. Juventudes na América Latina e no Caribe: dimensões sociais, subjetividades e estratégias de vida. In: THOMPSON, A. A. Associando-se à juventude para construir o futuro. São Paulo: Peirópolis, 2005. p. 166-169.

LUTTE, Gérard (ed.). Sopprimere l'adolescenza. I Giovani nella società post-industriale. Turín: Gruppo Abele, 1984.

MANNHEIM, Karl. O problema sociológico das gerações. In: FORACCHI, Marialice M. (org.). Mannheim. São Paulo: Ática, 1982. p. 67-95. (Os grandes cientistas sociais, n. 25).

MELUCCI, Alberto. A invenção do presente: movimentos sociais nas sociedades complexas. Trad. Maria do Carmo Alves do Bomfim. Petrópolis: Vozes, 2001.

MELUCCI, Alberto. Por uma sociologia reflexiva: pesquisa qualitativa e cultura. Trad. Maria do Carmo Alves do Bomfim. Petrópolis: Vozes, 2005.

NOVAES, Regina; VITAL, Cristina. A juventude de hoje: (re)invenções da participação social. In: THOMPSON, A. A. (org.). Associando-se à juventude para construir o futuro. São Paulo: Peirópolis, 2005.

ORTEGA, Francisco. Amizade e estética da existência em Foucault. Rio de Janeiro: Edições Graal LTDA, 1999.

ORTEGA, Francisco. Para uma política da amizade: Arendt, Derrida e Foucault. Rio de Janeiro: Relume-Dumará, 2000. 
ORTEGA, Francisco. Genealogia da amizade. São Paulo: Editora Iluminuras, 2002.

PAIS, José Machado. Culturas juvenis. 2. ed. Lisboa: Imprensa Nacional - Casa da Moeda, 2003.

PERONDI, Maurício. Narrativas de jovens: experiências de participação social e sentidos atribuídos às suas vidas. 2013. Tese (Doutorado em Educação) - Faculdade de Educação, Universidade Federal do Rio Grande do Sul, Porto Alegre, 2013.

RICOEUR, Paul. A memória, a história e o esquecimento. Campinas: Editora da Unicamp, 2007.

SECRETARIA NACIONAL DE JUVENTUDE - SNJ. Agenda Juventude Brasil 2013: pesquisa de opinião pública. Brasília, 2013. Disponível em: https://bit.ly/3aGmXDI. Acesso em: 25 maio 20.

URTEAGA, Maritza. La construcción juvenil de la realidad: jóvenes mexicanos contemporáneos. México: D.F. Casa Abierta al Tiempo; Juan Pablos Editor, 2011. 